\title{
MONANTROPISMo E MOVIMENTO PARA A PAZ NO PENSAMENTO DE VIKTOR FRANKL
}

\author{
MONANTROPISM AND THE MOVEMENT FOR PEACE \\ ACCORDING TO VIKTOR FRANKL
}

\section{Thiago Antonio Avellar Aquino* Josilene Silva Cruz** Eliseudo Salvino Gomes ${ }^{* * *}$}

\section{RESUMO}

O presente artigo tem como objetivo apontar as possibilidades de construção de uma cultura de paz a partir do conceito de monantropismo, segundo a Logoterapia e Análise Existencial de Viktor Frankl. Ademais, identificaram-se interlocuções entre a educação e a cultura de paz. Concluiu-se que, para se contrapor à cultura de guerra, torna-se necessário desenvolver o espírito de uma humanidade única, além de cultivar algumas virtudes fundamentais, tais como: a tolerância, o perdão, a responsabilidade coletiva e individual.

Palavras-chave: Monantropismo. Cultura de Paz. Logoterapia. Ensino Religioso.

\section{ABSTRACT}

This article aims to point out the possibilities of building a culture of peace based on the concept of Monantropismo according to the Logotherapy and Existential Analysis of Viktor Frankl. In addition, was identified interlocutions between the education and the culture of peace. It was concluded that, in order to counteract the culture of war, it is necessary to develop the spirit of a unique humanity, as well as cultivating some fundamental virtues, such as: tolerance, forgiveness, collective and individual responsibility.

Keywords: Monantropism. Culture of Peace. Logotherapy. Religious education.

\section{INTRODUÇÃO}

Em meados do século XX, Einstein constatou que "[...] nossa humana civilização descobre o novo sentido da palavra paz: significa sobrevivência.” (EINSTEIN, 1981, p. 59). Não obstante, em pleno século XXI, ainda se enfrenta os sintomas de um mundo ameaçado por guerras e conflitos, e sem um mapa para ajudar a reencontrar um caminho seguro para a paz. Outrora, a cultura judaico-cristã foi fundamental para proporcionar uma reflexão

\footnotetext{
${ }^{*}$ Doutor em Psicologia Social pela Universidade Federal da Paraíba (UFPB). Licenciado em Psicologia (UFPB). Professor do Departamento de Ciências das Religiões (UFPB). E-mail: logosvitae@hotmail.com.

${ }^{* *}$ Mestra em Ciências das Religiões pela Universidade Federal da Paraíba (UFPB). Doutoranda em Ciências das Religiões (PPGCR/UFPB). Licenciada em Ciências das Religiões (UFPB). E-mail: josileneufpb@gmail.com.

*** Doutor em Psicologia Clínica pela Universidad Pontificia de Salamanca (España) e Universidade Católica de Brasília. Licenciado em Psicologia (UEPB). E-mail: salvinno@hotmail.com.
} 
profícua acerca da paz, sobretudo, quando aventou a Regra de Ouro como uma primeira tentativa de mediação de conflitos.

Como prescrições negativas, essa norma aparece no contexto judaico nos livros de Tobias e no Levítico: o primeiro intenta que "Não faças a ninguém o que não queres que te façam.” (BÍBLIA, Tobias 4, 15); já o segundo sugere que "Não te vingarás e não guardarás rancor contra os filhos do teu povo.” (BÍBLIA, Levítico 19, 18). Já como um princípio positivo, a Regra de Ouro aparece no cristianismo, no Sermão da Montanha: "Tudo aquilo, portanto, que quereis que os homens vos façam, fazei-o vós a eles.” (BÍBLIA, Mateus 7, 12). Mais do que uma regra, este último preceito pode ser considerado um princípio, pois é prescrito de forma positiva. Atesta o Profeta Isaías: “[... ] o fruto da justiça será a paz; e a obra da justiça proporcionará tranquilidade e segurança eternas.” (BÍBLIA, Isaías 32, 17).

No reino animal, os seres agem por meio da reciprocidade, ou seja, em um contínuo ato de ação e reação, posto que não adentram à dimensão dos valores normativos nem se orientam por princípios de consciência. Já no reino humano, entre o estímulo e a reação agressiva, encontra-se a liberdade da vontade, que emerge ao decidir entre seguir os condicionantes externos e agir em direção à construção de uma ecologia para a paz.

Dessa forma, compreende-se que a questão da paz é uma preocupação especificamente humana e que pode estar relacionada à imagem de homem como um ser livre e responsável. Dessa forma, a educação para a paz requer uma pedagogia que desperte tanto a liberdade da vontade humana quanto o senso de responsabilidade. Nessa perspectiva, torna-se relevante abordar a temática da paz levando-se em conta uma concepção que abarque tais fenômenos humanos.

Destarte, o presente artigo tem por objetivo refletir acerca das possibilidades de construção de uma cultura de paz a partir do conceito de monantropismo, da logoterapia e análise existencial de Viktor Frankl. As perguntas que nortearam as reflexões foram: A paz poderia ser considerada um dever-ser e a guerra um não-dever-ser? Como tornar real a possibilidade da paz? O provérbio romano sugere que si vis pacem, para bellum, ou seja, se quer paz, prepare-se para a guerra; mas a guerra seria uma condição necessária para a paz? Para tentar responder a tais questionamentos, levou-se em conta a dinâmica espiritual para a busca de sentido na vida, como uma via para se obter o escopo do manuscrito. 


\section{IMAGEM DE HOMEM E CULTURA DA PAZ}

Viktor Frankl (1905-1997) foi um psiquiatra e neurologista vienense, que inaugurou uma escola de psicoterapia centrada na busca do sentido da vida denominada Logoterapia e Análise Existencial. Durante a Segunda Guerra Mundial, por ter origem judaica, ele foi perseguido e encaminhado inicialmente para o gueto de Theresienstadt epara os campos de concentração de Auschwitz, Kaufering e Türkheim (anexo ao campo de Dachau) onde realizou trabalhos forçados como prisioneiro comum sob o número 119.104. Sobrevivente do holocausto, prosseguiu sua carreira como médico, conferencista e escritor, levando a sua mensagem para a construção de um mundo pacífico.

Em 1984, quando proferiu conferências por ocasião do I Encontro Latino-Americano Humanístico-Existencial - Logoterapia, na PUC do Rio Grande do Sul, recebeu o título de Doutor Honoris Causa, concedido pelo Instituto de Psicologia da PUC-RS, por proposição da professora Izar Xausa, bem como foi indicado para o Prêmio Nobel da Paz, por iniciativa da mesma professora. Sobre o movimento da Logoterapia e a causa da paz, destaca-se o que comenta Xausa (2012):

Para que a promessa de paz não seja mentira, é preciso construir a paz, cultivar a paz, amar a paz. E nós todos que, aqui e agora, adeptos da Logoterapia, estamos reunidos para afirmar que ela é uma promessa verdadeira de paz; estamos reunidos para falar da dignidade da pessoa humana declarada pela Logoterapia, e estamos falando em nome do autor Viktor Frankl, que em sua vida sofreu martírio dos campos de concentração nazistas mantendo a sua dignidade e ensinando ao mundo uma das mais belas lições sobre a força de resistência do espírito humano. (XAUSA, 2012, p. 93).

Para uma reflexão benfazeja acerca da cultura de paz, torna-se necessário compreender quem afinal é o ser humano. Nessa perspectiva, destacam-se as palavras de um sobrevivente dos campos de concentração:

Nós aprendemos a conhecê-lo como talvez nenhuma outra geração anterior o tenha feito; nós o conhecemos no campo de concentração, onde lhe faltou tudo que havia possuído: dinheiro, fama, poder, felicidade, restando apenas o que o define como ser humano. Sobrou o que ele não pode 'ter', mas o que ele deve 'ser'. O que ficou foi o próprio homem, em sua essência, queimado pela dor, dissolvido pelo sofrimento - o elemento humano em sua quintessência. (FRANKL, 1978, p. 255).

O homem é um ser que decide continuamente entre mérito e culpa, pois é o ser que idealizou as câmaras de gás, mas o que também entrou nelas de cabeça erguida com uma oração nos lábios (FRANKL, 1978). É um ser aberto para a comunidade, que tem a 
especificidade humana de autotranscender e buscar um sentido para a sua existência em sua relação com o mundo; dessa forma, o autor define o ser humano a partir da pessoa espiritual.

$\mathrm{Na}$ ótica frankliana, o espiritual não pode ser reduzido exclusivamente ao senso religioso. Por esse motivo, o autor alerta:

Como, em língua inglesa, o termo 'espiritual' [spiritual] apresenta uma conotação religiosa, [...]. O que nós compreendemos como dimensão noológica se refere a uma conceituação antropológica, muito mais do que teológica. (FRANKL, 2011, p. 28).

A dimensão noológica ou espiritual abarca diversos fenômenos que são específicos do ser humano, tais como: a busca de sentido, a vontade de humor, a consciência intuitiva (Gewissen), a liberdade da vontade, a atração por valores éticos e estéticos, o amor, dentre outros aspectos que distinguem os homens dos animais. De forma mais específica, essa dimensão está relacionada com duas características antropológicas: a autotranscedência (lançar-se em direção a algo ou alguém no mundo) e o autodistanciamento (confrontar-se consigo mesmo, ou seja, com o psicofísico). O senso religioso, por sua vez, teria sua origem nesta dimensão, já que seria um fenômeno humano como tantos outros que não são compartilhados com os animais (FRANKL, 1989a, 1989b; 1978).

$\mathrm{O}$ autor em foco, em diversos momentos de sua obra, ressaltou esta perspectiva de uma visão de homem que se destaca pela sua unidade em função de um ponto comum, mas ele sempre levou em conta suas distinções, quando ele expõe o conceito de unitas multiplex, que de forma simplificada, pode-se definir como uma unidade apesar da multiplicidade, conforme demonstra Bruzzone (2011) ao tratar das dimensões antropológicas propostas por Frankl:

As três dimensões antropológicas, embora sejam distinguíveis, não são separáveis: constituem uma unitas multiplex, de acordo com a definição tomista. "Não se trata de uma unidade na multiplicidade, mas sim de uma unidade, apesar da multiplicidade". A complexidade do ser humano se manifesta como uma unidade unitária indivisível e uma totalidade insumável: "A personalidade é in-dividuum, não divisível, porque é uma unidade. Enquanto é in-sommabile porque é uma totalidade. Existe uma unidade antropológica e uma totalidade antropológica [...], apesar das diferenças ontológicas [...]. (BRUZZONE, 2011, p. 87, tradução nossa).

Desse modo, percebe-se que a concepção frankliana converge para aspectos antropológicos, os quais aproximam os seres humanos e promovem a sua identidade. 


\section{CONTRIbUiÇÕes PARA A PAZ SEGUNdo A ANÁlise EXISTENCIAL DE VIKTOR FRANKL}

O tema da paz remete a diversos desafios. De acordo com Torralba (2014), existem seis eixos temáticos para problematizar o assunto da paz: o primeiro é desarmar a história; o segundo é a relação entre as diferentes identidades; o terceiro é a justiça e as estruturas sociais, e este autor está seguro de que a paz tem fundamento na justiça e que sem justiça não haverá paz no mundo; o quarto é mediação e cultura de paz; o quinto são meios de comunicação e paz, e o sexto é repensar a democracia.

Ademais, "[...] uma vez que as guerras começam na mente dos homens, é na mente dos homens que as defesas da paz devem ser constituídas.” (UNESCO, 1945, p. 7). Nessa direção, um mecanismo da mente elucidado por Frankl (1978) foi que o medo do medo reforça o temor, assim como o medo da guerra seria a mola propulsora da própria guerra (Figura 1):

\section{Figura 1: Círculo vicioso reforçador da cultura de guerra}

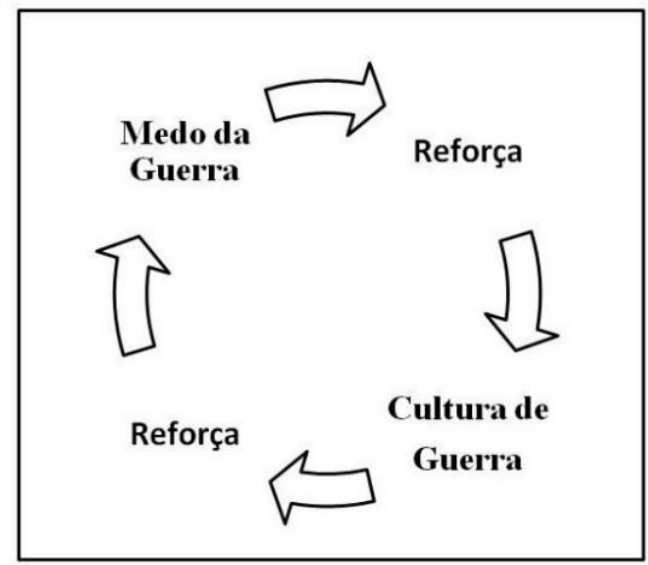

Fonte: Elaborado pelos autores

A cultura de guerra, por sua vez, propicia maiores investimentos no setor armamentício, reforçando a vontade de poder bélico. Entretanto, torna-se necessário desenvolver estratégias para romper esse círculo vicioso (FRANKL, 1978) e que, por conseguinte, recupere a confiança básica na paz mundial. Para tanto, torna-se imprescindível estar consciente acerca da situação real do mundo para que se desperte o senso de responsabilidade. Preocupado com as possíveis consequências de futuros conflitos, Frankl (1994) alerta: 
[...] o mundo está numa situação ruim. Porém, tudo vai piorar ainda mais se cada um de nós não fizer o melhor que pode.

Portanto fiquem alerta - alerta em duplo sentido:

Desde Auschwitz nós sabemos do que o ser humano é capaz.

E desde Hiroshima nós sabemos o que está em jogo. (FRANKL, 1994, p. 129).

O autor em questão apresenta algumas intuições para implementação de um movimento para a paz pautado em posturas e ações mais valorosas, como, por exemplo, o esforço em prol de uma tarefa comum:

Eu estou certo de que existe a esperança da sobrevivência da humanidade, dos homens, sempre que reconheçam que há uma tarefa comum que os espera [...]. Talvez a tarefa comum mais nobre e importante para a humanidade [...] seja o movimento de Paz em nível mundial [...]. (FRANKL, 1991a, p. 21-22).

Um exemplo de uma tarefa comum mais nobre ocorreu no caso dos doze meninos presos na caverna Tham Luang, na Tailândia, no dia 23 de junho de 2018, por ocasião de uma inundação provocada pelas chuvas. O fato mobilizou mil pessoas e especialistas de diversos países (Reino Unido, China, Mianmar, Laos, Austrália, Estados Unidos, Rússia, Finlândia, Suécia, Ucrânia e Israel). E, no dia 8 de julho no mesmo ano, todos tinham sido resgatados, passando por um trecho de quase $3 \mathrm{~km}$, entre passagens estreitas e áreas alagadas. Um dos mergulhadores, Rick Stanton, afirmou depois do êxito do resgate: “Se somos heróis? Não [...] Só estamos usando um conjunto de habilidades muito específicas que normalmente usamos para nosso próprio interesse, e às vezes podemos usá-las para devolver algo à comunidade." (NICHOLS, 2018).

Esse feito provavelmente tenha sido a experiência mais próxima da perspectiva de um sentido único que convergiu pessoas de diversas nações para uma única missão. Dessa forma, um genuíno paradigma para a cultura de paz requer que sejam desenvolvidas habilidades para a comunidade humana em um ato de autotranscendência. Nessa mesma direção, Frankl (1994) cita um exemplo acerca de como diminuir a agressão por meio da perspectiva de um sentido comum:

[...] desejo citar uma experiência levada a efeito certa vez por Carolyn Wood Sherife. Ela havia tido êxito em criar artificialmente agressões mútuas entre grupos de escoteiros, e observou que as agressões só cediam terreno quando os jovens se dedicavam a um objetivo comum - isto é, a tarefa conjunta de empurrar o veículo atolado na lama que trazia comida para seu acampamento. Eram imediatamente não só desafiados, mas também unidos por um sentido que tinham que realizar. (FRANKL, 1994, p. 122). 
Frankl, tomando como parâmetro a sua experiência nos campos de concentração, argumenta ainda que ter um sentido para a vida constitui tanto um valor de sobrevivência para o indivíduo, quanto para a humanidade em sua totalidade. Dessa forma, indaga: "Não deveríamos nós, no campo da pesquisa da paz, colocar a questão, se também para a humanidade a única chance estaria enfim na realização de uma tarefa comum a todos?” (FRANKL, 1990, p. 24). Em outras palavras, o caminho para a paz, segundo o autor, seria por meio de uma vontade comum em um sentido único (FRANKL, 1990), conforme descreve a seguir:

O ser-homem significa ser dirigido no rumo de, e subordinado a algo que é mais do que o indivíduo. A existência humana caracteriza-se pelo fato de transcender a si mesma. Tão logo a existência humana deixa de se transcender, o permanecer em vida se torna sem sentido e impossível. Foi pelo menos a lição que coube aprender [...] os prisioneiros mais aptos a suportar o cativeiro eram os que tinham algo por esperar, um objetivo no futuro, um sentido a realizar. Isso não deveria ser válido para toda a humanidade e sua sobrevivência? (FRANKL, 1978, p. 52-53).

Se a via régia para a paz requer um sentido único para a humanidade, então, não seria necessário apelar também para a responsabilidade coletiva? A construção de uma cultura de paz requer o apelo à consciência de cada ser humano e também de cada nação; logo, seria tanto uma responsabilidade individual quanto social. Para tornar a humanidade consciente dessa responsabilidade, Frankl (2011) recomendou a construção da Estátua da Responsabilidade na costa Oeste dos Estados Unidos, tendo em conta que a liberdade sem responsabilidade torna-se arbitrariedade. Esse ideal começou a se delinear com o encontro de Frankl e Stephen R. Covey, que levou em frente o projeto para a construção da Estátua da Responsabilidade, que teria a mesma altura da Estátua da Liberdade (Responsibility Foundation, 2019).

Além de encontrar tarefas e sentido comum, torna-se necessário cultivar algumas virtudes que promoveriam a paz, tais como o perdão e a tolerância. Frankl adotou uma postura de perdão, apesar de ter perdido quase toda a sua família em campos de concentração. Foi uma atitude concreta em prol da cultura de paz:

Enquanto continuarmos julgando e acusando o próximo, nunca chegaremos ao fundo da questão. Portanto, de nossa parte, não desejamos apenas evocar os mortos, mas também perdoar os vivos. E assim como por cima de todos os túmulos, estendemos a mão aos que morreram, assim, por cima de todos os ódios, queremos igualmente estendê-la aos que vivem. E quando proclamamos "honra aos mortos", logo acrescentamos: "e paz para todos os vivos de boa-vontade!”. (FRANKL, 1978, p. 256). 
O perdão poderia ser uma virtude que ajudaria a romper o círculo que reforça continuamente a cultura de guerra. Nessa perspectiva, Frankl (1994) argumenta que até mesmo aquele que foi vítima de injustiça não teria o direito de cometer injustiça, aventando que o ser humano pode tomar uma postura a favor da paz, o que aplacaria o ódio e a agressão. A dimensão espiritual se expressa na medida em que o ser humano pretere a possibilidade de agressão (dimensão compartilhada com os animais) e escolhe o caminho da reconciliação (fenômeno exclusivo do ser humano). A título de exemplo, Frankl faz o seguinte relato sobre a sua vivência no período da Segunda Guerra Mundial:

E citemos, do mesmo asilo, um jovem cirurgião, Dr. Paul Fürst, e outro médico, Dr. Ernest Rosemberg. Com ambos pude conversar antes de morrerem. E não havia ódio no que diziam. Aos seus lábios assomavam apenas palavras de saudade e de perdão. Pois o que eles odiavam e nós odiamos não são os homens - é o sistema. Aos homens, pode-se perdoar. O sistema que odiamos traz para uns, culpa, e para outros, morte. (FRANKL, 1978, p. 254).

Nesse sentido, torna-se fundamental separar o objeto do ódio da pessoa em si, o que levaria então à possibilidade de amar a pessoa, mas odiar o sistema. "[...] odiar alguma coisa é mais significativo do que odiar alguém (o criador ou dono daquilo que eu odeio), porque, se não odeio pessoalmente, posso ajudá-lo a vencer aquilo que nele odeio. Posso amá-lo, apesar daquilo que nele odeio.” (FRANKL, 1989a, p. 64). Essa distinção pode se desdobrar em outra virtude denominada de tolerância.

A tolerância seria uma condição necessária para a paz, pois significa, em última instância, aceitar as diferenças de convicções, crenças, comportamentos e orientações. Parte da aceitação do outro como ele é, sem imposições de opiniões e, por esse motivo, torna-se uma via para perceber harmonia apesar da diversidade, transformando a cultura de guerra em uma cultura de paz (UNESCO, 1995). Em última análise, “[...] precisamos da Paz porque ela garante a preservação do planeta na sua multiculturalidade e diversidades de todas as naturezas e níveis." (FREIRE, 2006, p. 391).

No campo de concentração, durante a Segunda Guerra Mundial, Frankl (1994) constatou que o prisioneiro ainda decidia que tipo de cárcere ele escolheria ser: santo ou porco, decente ou indecente, pois ambas as potencialidades estariam dentro de si, esperando por uma decisão pessoal. De forma análoga, a ecologia da paz e da guerra também estaria em potência na humanidade e, dependeria mais de escolhas do que de condições. 
Na esteira de uma estética da paz, Frankl desenvolveu o conceito de monantropismo ${ }^{1}$, tendo por base o conceito do monoteísmo. Da mesma forma que a humanidade partiu da multiplicidade de deidades e chegou a uma compreensão de um Deus uno, também poderíamos alcançar a compreensão de uma unidade na espécie humana, unidade apesar da multiplicidade religiosa, dos diversos matizes de pele e de estratificação social.

Há milhares de anos, a humanidade desenvolveu o monoteísmo. Hoje, um outro passo se faz exigir. Eu o chamaria de "monantropismo". Não a crença em um Deus único, mas, mais do que isso, a consciência da unidade do gênero humano; uma unidade sob cuja luz as diferentes cores de nossa pele desapareciam. (FRANKL, 2011, p. 124).

Em outro momento, Frankl expressa essa mesma ideia da forma como se segue: “[...] uma unidade que ultrapassa todas as diversidades, quer as da cor da pele, quer as da cor dos partidos [...]” (FRANKL, 1989b, p. 28). O monantropismo requer a superação das diferenças em prol de uma causa única: a de salvar a humanidade. Allers, professor de Viktor Frankl, expressou que “[...] todos os homens formam, juntos, uma unidade.” (ALLERS, 1958, p. 107). Mounier, por sua vez, compreendia que “[...] a unidade de um mundo de pessoas só se pode obter na diversidade de vocações e na autenticidade de adesões.” (MOUNIER, 2004, p. 65).

O monantropismo implica fundamentalmente na perspectiva da autotranscendência e da tolerância, e ele complementa essa defesa argumentando que, para que possamos desenvolver ou determinar valores e sentido que sejam aplicáveis à humanidade como um todo, “[...] então a humanidade, depois de ter passado milênios sob a influência do monoteísmo, deverá dar um grande passo adiante, encaminhando-se para o saber do homem. Aquilo de que mais precisamos hoje é um monantropismo.” (FRANKL, 1978, p. 53). Ou seja, é preciso ultrapassar os limites ofertados pelos sistemas religiosos para galgar um caminho comum: o da sabedoria humana.

Frankl chega à conclusão de que "[...] o sentido da individualidade só atinge plenamente na comunidade." (FRANKL, 1989b, p. 116). Dessa forma, compreende-se que (1) a comunidade corresponde à multiplicidade cultural, e (2) o ser humano se complementa apenas na sua comunidade, atingindo o seu sentido pleno apenas quando se lança para fora de si mesmo. Para tornar compreensível essa intuição, o autor relaciona as partes com o todo ao propor a metáfora do mosaico, pois, segundo ele,

\footnotetext{
${ }^{1}$ Neologismo formado pela união das palavras mono, do grego, mónos, que significa unidade, e anthropos, palavra grega que denota ser humano ou relativo ao humano.
} 
[...] cada um dos fragmentos, cada pedra, é, na forma e na cor, algo incompleto e ao mesmo tempo imperfeito; só no todo e para o todo significa cada uma alguma coisa. Se cada pedra - a modo de miniatura, digamos - contivesse já o todo, então poderia ser substituída por qualquer outra. (FRANKL, 1989b, p. 114).

Como partes, a pessoa é incompleta e imperfeita; entretanto, na comunidade e para a comunidade o ser humano torna-se único e irrepetível. Da mesma forma que não existem pessoas perfeitas, tampouco existem grupos perfeitos. Conforme pensa Frankl (1994):

[...] existem sobre a terra duas raças humanas e realmente apenas essas duas: a 'raça' das pessoas direitas e das pessoas torpes. Ambas as 'raças' estão amplamente difundidas. Insinuam-se e infiltram-se em todos os grupos: não há grupo constituído exclusivamente de pessoas decentes, nem unicamente de pessoas torpes. (FRANKL, 1994, p. 83).

Num mundo plural, Frankl adverte: "Somente pode haver uma verdade, mas ninguém pode saber se é ele e não o outro que a possui.” (FRANKL, 1992, p. 68). Destarte, também se torna necessário, para a paz mundial, alcançar primeiro a paz entre as religiões superando as acepções de verdade ou mesmo a sua tutoria, como muitos de seus líderes propagam cotidianamente. Dessa forma, concebe que:

O culto é apenas forma, apenas caminho. Quanto mais importa a meta, menos se atentará no caminho, que é simplesmente um dos meios de lá chegar. A isso se chama de tolerância. A fé não deve ser rígida, deve ser firme. Rigidez na fé suscita o fanatismo; firmeza se coaduna com uma atitude de tolerância. Quem não se sente firme em sua fé se agarra com ambas as mãos a um dogma inalterável; quem está seguro na sua fé dispõe das mãos livremente e as estende para os seus semelhantes, com os quais está em comunhão existencial. (FRANKL, 1978, p. 280).

Para incentivar a tolerância com ideias antagônicas e cosmovisões divergentes, Frankl compreende que nunca se terá a certeza de que a consciência de cada pessoa, em última instância, seja a correta, assim, é preciso ter humildade, posto que "Humildade significa também tolerância; mas tolerância não é o mesmo que indiferença; porque respeitar a fé dos que têm outras crenças não significa de nenhuma maneira identificar-se com a fé do outro.” (FRANKL, 1992, p. 83).

A partir dessa constatação, percebe-se que uma visão de mundo unilateral seria inconcebível na perspectiva frankliana, visto que a unidade na multiplicidade faz parte da estrutura ontológica do humano e de sua comunidade. Já o fanatismo, por sua vez, seria um fator de risco para a paz: “O homem induzido pelo fanatismo não enxerga o ser pessoal do outro, daquele que não sintoniza com o seu pensamento. Não admite ele um pensar diferente 
do seu. Para ele é válido, não o entendimento de outrem, mas somente a sua própria opinião.” (FRANKL, 1991b, p. 46).

Outrossim, Frankl já alertava para os perigos de se massificar o ser humano, quando se perde, sobretudo, a sua unidade. Assim considerava que: "Em sendo absorvido pela massa, perde o homem o que lhe é mais próprio e peculiar: a responsabilidade [...]. Mas esta tendência para fugir da responsabilidade é o motivo de todos os coletivismos." (FRANKL, 1989b, p. 118).

No coletivismo perde-se de vista a multiplicidade e tudo é considerado monocromático. Torna-se necessário romper com a dualidade que segrega a condição humana. Sobre isso, o autor relata sua vivência no Campo de Concentração:

Lembro-me que um dia um capataz (não-prisioneiro) furtivamente me passou um pedaço de pão. Eu sabia que ele só podia tê-lo poupado da sua merenda. O que me derrubou a ponto de derramar lágrimas não foi aquele pedaço de pão em si, e sim o afeto humano que esse homem me ofereceu naquela ocasião, a palavra e o olhar humanos que acompanharam a oferta... (FRANKL, 1994, p. 83).

A experiência de compaixão decorre do gesto, do olhar e da palavra que rompem o abismo entre essa oposição da condição humana, entre ser prisioneiro de um lado e ser capataz do outro. Assim conclui Frankl (1994, p. 83): “[...] a bondade humana pode ser encontrada em todas as pessoas e ela se acha também naquele grupo que, à primeira vista, deveria ser sumamente condenado.”.

Por conseguinte, o autor se posicionou contra a culpa coletiva, ou seja, o fato de responsabilizar alguém pela escolha de outrem seja a decisão de um indivíduo ou de um grupo, posto que essa atitude poderia ser um fator capaz de abalar a paz entre pessoas, grupos e também nações. Quando retornou a Viena, após a sua libertação dos campos, foi indagado com a seguinte pergunta: “Viena não machucou você e os seus o suficiente?” Ao que respondia:

Quem foi que me fez o quê? Havia uma baronesa católica em Viena que durante anos escondeu uma prima minha em sua casa, mesmo correndo o risco de morte. E havia também um advogado socialista que eu conhecia apenas superficialmente, que não tinha nenhum relacionamento comigo, mas sempre que possível me trazia algo. (FRANKL, 2010, p. 118).

Em outra ocasião, Frankl foi criticado por escrever livros em alemão, a mesma língua de Adolf Hitler. Sua resposta foi perguntar se aquela pessoa usava facas em sua cozinha, e 
quando respondeu que sim, exclamou: "Como é que você consegue usar facas se tantos assassinos já as usaram para apunhalar e matar suas vítimas?” (FRANKL, 1994, p. 126).

Com essa réplica ele demonstra sua oposição à culpa coletiva, pois considera o homem como um ser livre e, por conseguinte, responsável. Sua vontade livre se constitui na capacidade de escolher dentre as múltiplas possibilidades de ser. Assim, uns decidiram usar a liberdade para inventar as câmaras de gás e se tornar indecentes, enquanto outros entraram nas câmaras de gás, escolhendo em suas últimas áreas de liberdade a postura de que iriam partir dessa vida, e se tornar heróis e santos. Dessa forma é possível tornar-se outro, independentemente do grupo ao qual pertença.

\section{MONANTROPISMO E EDUCAÇÃO PARA A PAZ}

Ao discorrer sobre a necessidade de se trazer à tona o diálogo sobre a cultura de paz, deparou-se com o desafio de buscar na prática um campo propício para tal debate, e com isso, constata-se que sua abordagem na formação do educando pode ser um fator de transformação social. No entanto, ainda é necessário perceber que o tema da paz é transdisciplinar e multidisciplinar, pois vislumbra a formação humana integral do educando e, portanto, leva-se em conta todas as dimensões, incluindo a dimensão espiritual denominada por Frankl (2011) noológica. Viktor Frankl ensina que para implementar uma cultura de paz torna-se necessário abarcar a totalidade da multiplicidade humana (biopsico-espiritual), no sentido de contribuir com uma sociedade mais humana e tolerante com as diferenças, no que se refere à valorização da dignidade da pessoa humana, independentemente de cor de pele, filosofias de vida, cosmovisões, tradição(ões) religiosa(s), entre outras distinções e/ou formas de expressão das diferenças presentes em nossa sociedade.

O Monantropismo, na perspectiva de uma humanidade única, requer a compreensão de que todo ser humano, independentemente da sua condição, tem um valor incondicional para a sua comunidade. Logo, é preciso desde cedo inserir o debate na vida dos educandos, pois estamos conectados em uma teia de relações formando uma unidade apesar da diversidade. A paz requer a descoberta de sentidos ou valores hierarquicamente mais elevados na comunidade humana, que brilhem na consciência a tal ponto que ofusquem as diferenças e rivalidades entre os grupos e pessoas. Para tanto, é uma condição necessária ampliar a percepção do campo de liberdade e das escolhas, para podermos cada vez mais 
prevenir as ações e atitudes de intolerâncias. Elisabeth Lukas (1990) compreende que "[...] 'tolerância pressupõe forte orientação para o sentido, ao passo que a intolerância é um sinal' - não de uma ausência de sentido ou apenas ausência de sentido, 'mas de uma orientação de sentido unilateral, reveladora de estreiteza mental'.” (LUKAS apud FUNKE, 1990, p. 112).

Para ampliar o espectro de sentido, pode-se estimular em sala de aula, e também para o seio do contexto escolar, ações e práticas que possibilitem a realização de uma missão comum, que possa unir a diversidade humana. É preciso enfatizar cada vez mais que é responsabilidade da escola promover tais virtudes, pois a educação, segundo Frankl (2011), deveria confrontar os jovens com ideais e valores mais nobres.

De acordo com Funke (1990) "[...] tudo aquilo que tem sido dito no âmbito da logoterapia a respeito da procura e dos processos de encontro de sentido pode ser, sem mais, aplicado à aprendizagem e educação da capacidade para a paz." (FUNKE, 1990, p. 112). Para o referido autor, a busca de sentido é indissociável em relação à capacidade para paz, pois toda ameaça destrutiva ou resulta na perda de valores, gerando apatia; ou desafia a humanidade a descobrir novos sentidos para a sua sobrevivência. Portanto, contextos educacionais podem ajudar nessa descoberta por meios dos recursos espirituais disponíveis nos educandos.

A educação capaz de potencializar a paz deve aproximar o ser do seu dever-ser, como assevera Frankl:

Segundo Heidegger, o homem se antecipa a si mesmo. [...] Aplicado ao homem, é o homem como ele deve ser, uma antecipação do homem como ele é. Assim, este 'serantecipadamente' é a condição de toda a possibilidade de existir, de toda possibilidade de ser 'de outro modo', de chegar a ser de outro modo, de toda autodeterminação, de toda autoformação e toda autoeducação. (FRANKL, 1978, p. 269).

Essa prerrogativa abordada por Frankl, apoiada no pensamento de Heidegger, corrobora com a promoção da cultura de paz, que, nesse caso, torna-se evidente quando se articula o dever-ser com o cuidado consigo e ao mesmo tempo com a coletividade; e nas palavras de Heidegger, o ser-antecipadamente como possibilidade de ser mais que si mesmo, mais que os pensamentos, e mais que as ações individuais, pois, ao pensar e priorizar o outro, estar-se atuando de outro modo, superando a individualidade e partindo para a busca de um bem comum para a coletividade, que possa, por consequência, proporcionar a paz. 
É importante frisar que "[...] a educação voltada para a cultura de paz inclui a promoção da compreensão, da tolerância, da solidariedade e do respeito às identidades nacionais, raciais, religiosas, por gênero e geração, entre outras, enfatizando a importância da diversidade cultural." (NOLETO, 2010, p. 13).

Mas afinal, pode-se ensinar para a paz? Nessa perspectiva, Frankl (2011) relata um diálogo com o filósofo de Harvard, Huston Smith, quando o indagou se era possível ensinar valores. A sua resposta foi: "Valores não podem ser ensinados; valores devem ser vividos." (FRANKL, 2011, p. 109). De forma semelhante, o ensino para a paz deve iniciar na vivência do próprio educador, sobretudo em sua esperança em um mundo mais belo, ou seja, naquele esperançar ativo, no qual é possível transformar os aspectos negativos do mundo em positivos por meio de atos criativos (FRANKL, 1994).

\section{CONSIDERAÇÕES FINAIS}

À guisa de conclusão, seguem as respostas às questões levantadas no manuscrito. As considerações supracitadas acerca da cultura de paz, na ótica de Viktor Frankl, apontaram para o monantropismo como uma condição necessária para a paz, na medida em que as diferenças culturais e raciais são abandonadas, em prol da união da humanidade para uma tarefa e/ou sentido comum. Assim, poderia enfatizar-se a identidade única: o gênero humano. Dessa forma, é necessário que educadores e educandos assumam um compromisso com uma tarefa comum mais nobre que perpassa pelo bem da comunidade humana, para construir, por consequência, uma cultura de paz.

Dessa forma, conclui-se que o pensamento desse autor é relevante para edificar caminhos exitosos para a paz. Para tanto, torna-se necessário conscientizar a pessoa de que é livre e responsável por suas escolhas e ações, o que por si só poderia aplacar conflitos derivados da culpa coletiva.

Ademais, a partir da leitura das obras de Frankl, considera-se que é possível, por meio da tolerância, do perdão e da responsabilidade coletiva, romper o círculo reforçador da cultura de guerra. Agora ainda resta responder às questões levantadas no início do artigo, para alargar o horizonte e clarificar novos caminhos para o estudo da paz.

\subsection{A paz poderia ser considerada um dever-ser e a guerra um não-dever-ser?}

Frankl (1994) relata em suas memórias sobre os campos de concentrações, que, 
quando exaustos, um dos companheiros chamou a atenção dos demais para o pôr do sol. Isso chama a atenção do leitor para perceber entre o contraste das cores do céu e os barracos cinzentos do campo. O silêncio da contemplação é quebrado quando alguém exclama: “O mundo poderia ser belo!” (FRANKL, 1994, p. 45). Essa imagem retrata também a situação do mundo atual, quando o cinza das guerras (o não-dever-ser) é quebrado pelos vislumbres de esperança em um mundo mais belo, quando anunciado pela grandeza de homens e mulheres como Madre Tereza de Calcutá, Malala Yousafzai, Mahatma Gandhi, Martin Luther King, dentre outros. Nesse sentido, poder-se-ia dizer que a cultura de paz consiste numa série de valores atitudinais, e comportamentos que rechaçariam a violência, extirpando todo tipo de intolerância através do diálogo e da negociação entre pessoas e nações.

\subsection{Como tornar real a possibilidade da paz?}

Xausa (1986) considera ser necessário transcender as condições limitadoras para a realização da cultura de paz, tais como as fronteiras políticas e ideológicas. Assim, a humanidade deveria "Transcender às limitações históricas para alcançar o bem comum dos homens e dos povos, a realização da esperança, a concretização da finalidade última do homem no planeta Terra." (XAUSA, 1986, p. 227).

Frankl, por sua vez, costumava citar as palavras do poeta alemão Goethe: "Se tomamos os homens como eles são, fazemo-los piores; mas se os tomamos como eles devem ser, faremos deles o que podem ser.” (XAUSA, 1986, p. 227). Da mesma maneira, para a construção de uma cultura de paz, deveremos considerar o que a humanidade deveria ser, para assim atingir o que ela pode ser. Assim como todo poder ser, para ser concretizado, depende da decisão humana, também a potencialidade da cultura da paz, para ser atingida, depende da escolha livre de cada ser humano.

\subsection{O provérbio romano sugere que 'si vis pacem, para bellum', ou seja, se quer paz, prepare-se para a guerra; mas a guerra seria uma condição necessária para a paz?}

Tomado por um espírito de justiça, o papa Paulo VI, em uma mensagem no dia 8 de dezembro de 1967, conclama a todos os povos que se celebre em $1^{\circ}$ de janeiro de 1968 o Dia Mundial da Paz. Enfatiza que o seu desejo é que depois, a cada ano, esta celebração viesse a 
se repetir, como augúrio e promessa, no início do calendário que mede e traça o caminho da vida humana no tempo que seja a Paz.

Portanto, celebra-se no ano de 2018 cinquenta anos da instituição do Dia Mundial da Paz, independentemente de credo, etnia, posição social ou econômica; pois na sua gênese a proposta de dedicar à paz o primeiro dia do novo ano não possuía a pretensão de ser qualificada como exclusivamente religiosa. Antes, seria para desejar que ela encontrasse a adesão de todos os verdadeiros amigos da paz, caráter sincero e forte de uma humanidade consciente e liberta dos seus tristes e fatais conflitos bélicos, e que daria à história do mundo um devir mais feliz, ordenado e civil.

Na obra de Frankl (2003), Lo que no está escrito en mis libros, nota-se que ele nutria uma estreita amizade com o papa Paulo VI. Nessa obra Frankl fala que tanto ele quanto sua esposa estiveram profundamente impressionados pela receptividade de Paulo VI, por ocasião de uma audiência no Vaticano. Isso atesta o respeito entre Judeu e Cristão-Católico, e o reconhecimento de todo o bem praticado por ambos. Da parte de Paulo VI fica o reconhecimento da importância da Logoterapia não só para a Igreja Católica, mas para toda a humanidade. Entretanto, o que mais impressionou a Frankl foi o que ouviu na despedida: “Por favor, reze por mim!” (FRANKL, 2003, p. 149). Um paradigma para alcançar uma unidade, apesar da diversidade religiosa.

A valorização da diversidade cultural seria fundamental para o incentivo da superação da intolerância. Ao buscar a valorização da diversidade cultural, instigar a suplantação das diferenças, estará promovendo aquilo que tem de mais significativo no gênero humano: a identidade como única espécie capaz de escolher, conviver com as distinções, vislumbrando a unidade em harmonia com a multiplicidade.

Frankl (1991b) apela para uma ética do sentido já que existem meios que podem profanar o fim; dessa forma, a guerra, como um meio para obter a paz, não se justificaria, pois dessacralizaria a meta final. As novas gerações poderiam ser educadas também para uma ética da paz, na qual compreendessem que a guerra não seria um meio válido para justificar a pacificação no mundo. Por este motivo, o autor concebe que não se deveria lutar pela paz, mas trabalhar por ela.

Em conclusão, compreende-se que a via para paz, segundo o pensamento de Viktor Frankl, deveria ser o engajamento em uma causa comum em favor do planeta Terra, capaz de unir as pessoas e lhes proporcionar sentido, e propósito para a humanidade como um todo, tendo como consequência adicional a sua própria sobrevivência. Para tanto, a 
educação poderia desempenhar um papel fundamental de cooperar com a quebra dos círculos que reforçam as agressões e as ações de intolerâncias entre grupos distintos, que transcendem por meio de uma busca de sentido, o que despertaria a consciência de que existe apenas uma humanidade, apesar de suas múltiplas colorações.

\section{REFERÊNCIAS}

ALLERS, Rudolph. Psicologia do caráter. Rio de Janeiro: Livraria Agir Editora, 1958.

BÍBLIA DE JERUSALÉM. Língua portuguesa. São Paulo: Paulinas, 1985.

BRUZZONE, Daniele. Afinar la consciencia: educación y búsqueda de sentido a partir de Viktor E. Frankl. Buenos Aires: San Pablo, 2011.

EINSTEIN, Albert. Como vejo o mundo. Rio de Janeiro, Nova Fronteira, 1981.

FRANKL, Viktor. Fundamentos antropológicos da psicoterapia. Rio de Janeiro: Zahar, 1978.

FRANKL, Viktor. Um sentido para a vida: psicoterapia e humanismo. Aparecida: Editora Santuário, 1989a.

FRANKL, Viktor. Psicoterapia e sentido da vida. São Paulo: Quadrantes, 1989b.

FRANKL, Viktor. A questão do sentido em psicoterapia. Campinas: Papirus, 1990.

FRANKL, Viktor. La psicoterapia y la dignidad de la existencia. Buenos Aires: Almagestos, 1991a.

FRANKL, Viktor. Psicoterapia para todos. São Leopoldo: Sinodal; Petrópolis: Vozes, 1991b.

FRANKL, Viktor. A presença ignorada de Deus. Petrópolis: Vozes, 1992.

FRANKL, Viktor. Em busca de sentido: um psicólogo no campo de concentração. São Leopoldo: Sinodal; Petrópolis: Vozes, 1994.

FRANKL, Viktor. Lo que no está escrito en mis libros: memorias, $2^{\mathrm{a}}$ ed. Buenos Aires: San Pablo, 2003.

FRANKL, Viktor. A vontade de sentido: fundamentos e aplicações da logoterapia. São Paulo: Paulus, 2011.

FREIRE, Ana Maria. Educação para a paz segundo Paulo Freire. Revista Educação. Pontifícia Universidade Católica do Rio Grande do Sul, Porto Alegre: PUC/RS, ano XXIX, n. 2, p. 387-393, maio/ago. 2006. 
FUNKE, Günter. Busca de sentido e capacidade para a paz. In: FRANKL, Viktor Emil (Org). Dar sentido à vida: a logoterapia de Viktor Frankl. Petrópolis: Vozes; São Leopoldo: Editora Sinodal, 1990, p. 99-112.

MOUNIER, Emmanuel. O personalismo. São Paulo: Centauro Editora, 2004.

NICHOLS, Henry. Mergulhadores Britânicos dizem se sentirem aliviados, não heróis, após resgate na Tailândia. 13 jul. 2018. Disponível em:

https://www.terra.com.br/noticias/mundo/mergulhadores-britanicos-dizem-se-sentiraliviados-nao-herois-apos-resgate-na-

tailandia,5aac4b43ab86c2agf1b8a5fc4b23ecbd2ec2dljx.html. Acesso em: 27 dez. 2019.

NOLETO, Marlova Jovchelovitch. A construção da cultura de paz: dez anos de história. In: UNESCO. Cultura de paz: da reflexão à ação; balanço da Década Internacional da Promoção da Cultura de Paz e Não Violência em Benefício das Crianças do Mundo. Brasília: UNESCO; São Paulo: Associação Palas Athena, 2010.

RESPONSIBILITY FOUDATION. Disponível em:

https://pt.slideshare.net/JohnHesseII/responsibilityfoundationstory1 Acesso em: 27 dez. 2019.

TORRALBA, Francesc. La paz. Barcelona: Milenio, 2014.

UNESCO. Constituición de la Organización de las Naciones Unidas para la Educación, la Ciência y la Cultura. Aprobada en 1945 y modificada. Paris: Unesco, 2012. Disponível em:

http://unesdoc.Unesco.org/images/o021/o02161/216192s.pdf\#page=7. Acesso em: 27 dez. 2019.

UNESCO. Declaration of Principles on Tolerance. 1995. Disponível em:

http://portal.unesco.org/en/ev.php-

URL_ID=13175\&URL_DO=DO_TOPIC\&URL_SECTION=201.html.Acesso em: 27 dez. 2019.

XAUSA, Izar Aparecida de Moraes. Viktor Frankl entre nós: a história da Logoterapia no Brasil e integração pioneira da Logoterapia na América Latina. Porto Alegre: EdiPUCRS, 2012.

XAUSA, Izar Aparecida de Moraes. A psicologia do sentido da vida. Petrópolis: Vozes, 1986.

Recebido em: 28.07 .2018

Aprovado em: 01.07.2019 